\title{
Penilaian Kepuasan Konsumen Menggunakan Metode Fuzzy Tsukamoto pada Produk Knalpot di R1 Racing Exhaust Sokaraja
}

\author{
Assessment of Customer Satisfaction Using Fuzzy Tsukamoto Method \\ in Muffler Products R1 Racing Exhaust Sokaraja \\ Marwazi Hibban Uchyana ${ }^{1}$, Hindayati Mustafidah ${ }^{2}$ \\ ${ }^{1,2}$ Teknik Informatika- Universitas Muhammadiyah Purwokerto \\ ${ }^{1}$ marwazihibbanchyayan@gmail.com \\ ²h.mustafidah@ump.ac.id
}

\begin{abstract}
ABSTRAK
Kepuasan konsumen merupakan isu yang kritikal di semua industri baik jasa dan perdagangan. Pada hakikatnya tujuan bisnis adalah untuk menciptakan dan mempertahankan para pelanggan sebagaimana pada R1 Racing Exhaust yang merupakan sebuah industri knalpot dan memerlukan umpan balik dari para konsumen untuk mengetahui tingkat kepuasan konsumen terhadap produk knalpot R1 Racing Exhaust, sehingga perlu dibangun sistem penilaian kepuasan konsumen dengan menerapkan metode Fuzzy Tsukamoto sebagai proses perhitungannya. Terdapat 2 jenis variabel yang digunakan yaitu variabel Fuzzy dan variabel non Fuzzy. Variabel Fuzzy yaitu kualitas produk dan kualitas pelayanan. Kualitas produk dibagi menjadi sub variabel pengelasan dan pewarnaan. Kualitas Pelayanan dibagi menjadi sub variabel waktu pengerjaan, komunikasi, daya tanggap (responsivenees) dan keramahan. Variabel non Fuzzy yaitu harga dan garansi sedangkan untuk variabel output-nya yaitu kepuasan konsumen. Dalam sistem penilaian yang dibuat menggunakan 54 aturan Fuzzy. Hasil dari penilaian ini berguna untuk pihak industri sebagai bahan evaluasi ke depannya agar dapat mendorong terciptanya loyalitas pelanggan dan meningkatkan laba yang menguntungkan perusahaan.
\end{abstract}

Kata Kunci: Kepuasan Konsumen, Logika Fuzzy, Tsukamoto

\begin{abstract}
Customer satisfaction is a critical issue in all services and trade industries. In essence the business objective is to create and maintain customers as in the Racing Exhaust Rl which is an exhaust industry and requires feedback from consumers to determine the level of customer satisfaction with RI Racing Exhaust exhaust products, so a customer satisfaction assessment system needs to be built by applying the method Fuzzy Tsukamoto as the calculation process. There are 2 types of variables used, namely Fuzzy variables and non Fuzzy variables. Fuzzy variables are product quality and service quality. Product quality is divided into sub variables, welding and coloring. Service Quality is divided into sub-variables of work time, communication, responsiveness and friendliness. Non Fuzzy variables are price and warranty, while for the output variable, namely customer satisfaction. In the scoring system made using 54 Fuzzy rules. The results of this assessment are useful for the industry as an evaluation material in the future so that it can encourage the creation of customer loyalty and increase profits that benefit the company.
\end{abstract}


Keywords: Customer Satisfaction, Fuzzy Logic, Tsukamoto Method Pendahuluan

\section{PENDAHULUAN}

Perkembangan ilmu pengetahuan dan teknologi yang semakin maju berpengaruh pada banyak aspek, salah satunya adalah aspek ekonomi dan juga bisnis. Hal ini mendorong perkembangan dunia usaha yang semakin pesat dan persaingan pasar semakin ketat. Semakin ketatnya persaingan dalam dunia bisnis saat ini, membuat perusahaan saling bersaing dalam menawarkan keunggulan produknya masing-masing. Sementara itu konsumen semakin selektif dalam memilih suatu barang atau jasa yang mereka butuhkan. Oleh karena itu setiap perusahaan harus dapat memahami dan memenuhi kebutuhan konsumen agar produknya mampu bersaing dengan para pesaingnya. Cara yang dilakukan adalah menerapkan strategi pemasaran yang efektif dan efisien serta kebijakan yang tepat untuk mempertahankan kelangsungan usahanya.

Kepuasan konsumen merupakan isu yang kritikal di semua industri baik jasa maupun perdagangan. Menurut Kotler dan Keller (2007), kepuasan konsumen adalah perasaan senang atau kecewa seseorang yang muncul setelah membandingkan kinerja/hasil produk yang dipikirkan terhadap kinerja yang diharapkan. Pelanggan merasa puas kalau harapan mereka terpenuhi, dan merasa amat gembira kalau harapan mereka terlampaui (Kottler, 1997). Kepuasan konsumen tercapai bila kebutuhan, keinginan dan harapan pelanggan terpenuhi, maka kepuasan konsumen telah tercipta (Tjiptono, 2005). Memuaskan kebutuhan konsumen dapat meningkatkan keunggulan dalam persaingan. Konsumen yang puas terhadap produk dan jasa pelayanan cenderung untuk membeli kembali produk dan menggunakan kembali jasa pada saat kebutuhan yang sama muncul kembali di kemudian hari. Dalam hal ini juga tidak menutup kemungkinan pelanggan akan memberitahukan orang lain mengenai pengalamannya terhadap kualitas produk yang telah digunakannya. Menurut Tjiptono (1994), adanya kepuasan pelanggan dapat memberi manfaat seperti: hubungan antara perusahaan dan para pelanggan menjadi harmonis, memberikan dasar yang baik bagi pembelian ulang, dapat mendorong terciptanya loyalitas pelanggan, membentuk suatu rekomendasi dari mulut ke mulut yang menguntungkan bagi perusahaan, reputasi perusahaan menjadi baik di mata pelanggan, laba yang diperoleh dapat meningkat. Ada lima dimensi atau artibut yang mempengaruhi kepuasan pelanggan yaitu kualitas produk, harga, service quality, emotional factor, biaya dan kemudahan mendapatkan produk (Lupiyoadi, 2001). Pelayanan adalah produkproduk yang tidak kasat mata (tidak dapat diraba) yang melibatkan usaha-usaha manusia dan menggunakan peralatan (Ivancevich, dkk., 1997). Sementara itu, pelayanan menurut Gronroos (1990) adalah suatu aktifitas atau serangkaian aktivitas yang bersifat tidak kasat mata (tidak dapat diraba) yang terjadi sebagai akibat adanya interaksi antara konsumen dengan karyawan atau hal-hal lain yang dimaksudkan untuk memecahkan permasalahan konsumen atau pelanggan. Parasuraman dkk. (1985) menyimpulkan bahwa kualitas pelayanan adalah harapan sebagai keinginan para pelanggan ketimbang layanan yang mungkin diberikan oleh perusahaan.

Knalpot merupakan bagian penting dalam mekanisme kendaraan bermotor. Bagian tersebut berfungsi berguna meredam tekanan gas buang yang dihasilkan setelah pembakaran di dalam mesin. Munculnya trend knalpot custom baik untuk mobil maupun motor juga menjadi salah satu penyebab berdirinya industri knalpot. R1 Racing Exhaust adalah salah satu industri knalpot yang berdiri di Sokaraja, berdekatan dengan daerah Purbalingga yang merupakan salah satu kota penghasil knalpot terbesar di Indonesia. Banyaknya pabrik knalpot yang berdiri, menyebabkan persaingan semakin ketat. Penurunan pendapatan sedang dirasakan R1 Racing Exhaust yang diakibatkan karena berkurangnya konsumen yang datang. Banyak faktor yang menyebabkan penurunan 
kedatangan konsumen, seperti adanya industri lain yang menawarkan harga yang lebih murah, kualitas produk yang mungkin kurang baik, atau kualitas pelayanan yang kurang memadai. Pemilik bengkel R1 Racing Exhaust ingin mengetahui penyebab pasti mengenai penurunan pendapatan yang dialaminya akhir-akhir ini.

Logika fuzzy merupakan suatu cara untuk memetakan permasalahan dari ruang input menuju ke ruang output yang diharapkan. Konsep matematis yang mendasari penalaran fuzzy sangat sederhana dan mudah dimengerti (Kusumadewi dan Purnomo, 2004). Logika fuzzy merupakan bagian dari logika Boolean, namun logika fuzzy memiliki banyak nilai. Tidak seperti elemen yang dikategorikan $100 \%$ ini atau itu, atau sebuah dalil yang menyatakan semuanya benar atau seluruhnya salah, fuzzy membaginya dalam derajat keanggotaan dan derajat kebenaran, yaitu sesuatu yang dapat menjadi sebagian benar dan sebagian salah pada waktu yang sama (Mustafidah, 2013). Logika fuzzy sudah banyak diterapkan di berbagai bidang, di antaranya bidang pendidikan (Mustafidah dan Aryanto, 2012), perikanan (Suwarsito dan Mustafidah, 2015), dan ekonomi (Fasanghari dan Roudsari, 2008; Singh dkk., 2014; Agustin dan Irawan, 2015; Abza, 2018). Berbagai teori di dalam perkembangan logika Fuzzy dapat digunakan untuk memodelkan berbagai sistem. Bahkan sekarang ini aplikasi logika fuzzy semakin menjamur seiring dengan pesatnya perkembangan teknologi komputasi. Penelitian aplikasi logika fuzzy menggunakan inferensi telah banyak dilakukan. Pada sistem fuzzy metode Tsukamoto, setiap konsekuen pada aturan yang berbentuk IF-THEN harus direpresentasikan dengan suatu himpunan fuzzy dengan fungsi keanggotaan yang monoton. Penilaian kepuasan konsumen dengan menggunakan logika fuzzy metode Tsukamoto dapat digunakan untuk menghitung penilaian agar mengetahui tingkat kepuasan konsumen R1 Racing Exhaust, sehingga dapat menjadi bahan evaluasi untuk selanjutnya.

Bahasa pemrograman yang digunakan untuk membangun sistem fuzzy ini adalah Java 2 yang merupakan generasi kedua dari Java platform (Sukamto dan Salahuddin, 2014). Kelengkapan lainnya digunakan Netbean sebagai Integrated Development Environment (IDE) dari Sun Microsystems (Nofriadi, 2015). Pembangunan database sistem ini digunakan MySQL yang merupakan database unik yang memungkinkan pendekatan yang berbeda untuk menyimpan dan mengakses data melalui konsep mesin penyimpanan (Curioso, 2010).

\section{METODE PENELITIAN}

Penelitian ini adalah jenis penelitian pengembangan untuk membangun sebuah sistem baru untuk mengetahui tingkat kepuasan konsumen menggunakan konsep logika fuzzy metode Tsukamoto pada produk R1 Racing Exhaust Sokaraja. Variabel yang digunakan dalam penelitian ini terdiri dari 2 jenis variabel yaitu variabel fuzzy dan variabel non-fuzzy. Variabel fuzzy berupa kualitas produk dan kualitas pelayanan. Kualitas produk dibagi menjadi sub variabel pengelasan dan pewarnaan. Kualitas pelayanan dibagi menjadi sub variabel waktu pengerjaan, komunikasi, daya tanggap (responsivenees) dan keramahan. Variabel non-fuzzy berupa harga dan garansi. Variabel output-nya yaitu kepuasan konsumen. Teknik pengumpulan data yang digunakan adalah wawancara, observasi, dan dokumentasi. Secara garis besar, langkah penelitian dapat dilihat pada Gambar 1. 


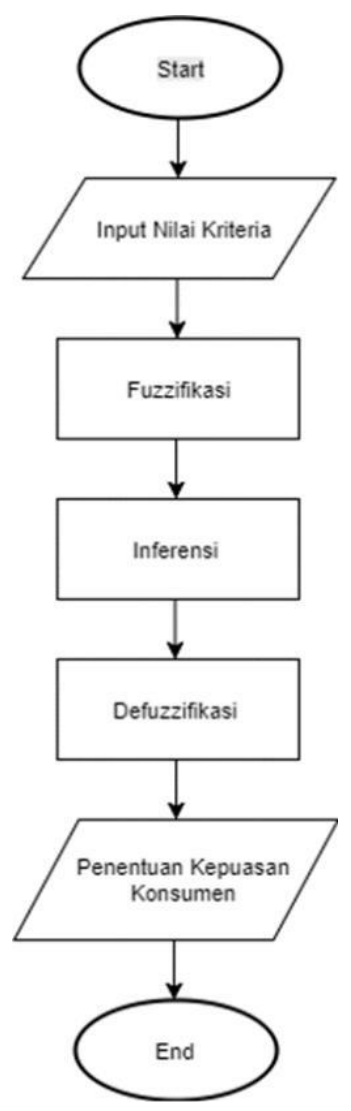

\section{Gambar 1. Langkah penelitian}

Input dari nilai variabel kualitas produk, nilai kualitas pelayanan, harga dan garansi. Fuzzifikasi diartikan mengambil masukan berupa nilai crisp dari input, membentuk himpunan fuzzy, membagi variabel input menjadi satu atau lebih himpunan fuzzy, dan menentukan derajat keanggotaannya. Inferensi dimaknai sebagai mengaplikasikan aturan pada masukan fuzzy yang dihasilkan dalam proses fuzzifikasi, mengevaluasi hubungan atau derajat keanggotaan anteceden dengan menggunakan fungsi min dan menentukan nilai $z_{i}$ pada setiap aturan yang digunakan. Pada tahap defuzzifikasi yaitu mengubah nilai yang dihasilkan pada proses inferensi untuk mencari nilai $\mathrm{Z}$ akhir. Pada penentuan Kepuasan Konsumen. Nilai Z dimasukkan pada kurva kepuasan konsumen untuk menentukan output berupa derajat kenggotaan yang kemudian diubah menjadi persentase dan mengambil kesimpulan berupa tingkat kepuasan konsumen.

\section{HASIL DAN PEMBAHASAN}

Sistem penilaian kepuasan konsumen pada produk R1 Racing Exhaust Sokaraja dihasilkan dari nilai setiap kriteria. Data tersebut diperoleh dari penilaian konsumen R1 Racing Exhaust Sokaraja dan kemudian diolah menggunakan metode logika fuzzy Tsukamoto yang meliputi beberapa tahapan.

\section{Input Kriteria}

Kriteria dalam penelitian ini berupa variabel input yaitu kualitas produk, kualitas pelayanan, harga dan garansi. Keterangan perhitungan nilai pada variabel input dapat dilihat pada Tabel 1. 
Variabel harga dan garansi bersifat non-fuzzy. Harga menggunakan perbandingan harga pasar, maka untuk derajat keanggotaannya 1 apabila harga lebih murah dari harga pasar dan 0,5 apabila harga sama serta 0 apabila harga lebih mahal dari harga pasar. Kemudian untuk garansi yaitu 1 apabila ada, dan 0 apabila tidak ada garansi.

\section{Tabel 1. Variabel Input Kriteria}

\begin{tabular}{cll}
\hline \multicolumn{1}{c}{ Kriteria } & Sub Kriteria & Perhitungan Nilai \\
\hline Kualitas Produk & Pewarnaan & Nilai Pewarnaan (1-10) \\
& Pengelasan & Nilai Pengelasan (1-10) \\
& Nilai Rata-Rata & Total Nilai Kualitas Produk / 2 \\
Kualitas Produk & \\
Kualitas Pelayanan & Waktu Pengerjaan & Nilai Waktu Pengerjaan (1-10) \\
& Komunikasi & Nilai Komunikasi (1-10) \\
& Daya Tanggap & Nilai Daya Tanggap (1-10) \\
& Keramahan & Nilai Keramahan (1-10) \\
& P Nilai Rata-Rata & Total Nilai Kualitas \\
& Kualitas & \\
& Pelayanan & Pelayanan / 4 \\
\hline
\end{tabular}

\section{Fuzzifikasi}

Setelah nilai dari tiap kriteria didapatkan, kemudian masuk pada tahap fuzzifikasi yaitu mencari nilai derajat keanggotaan. Representasi dari variabel input pada penelitian ini dapat dilihat pada Gambar 2.

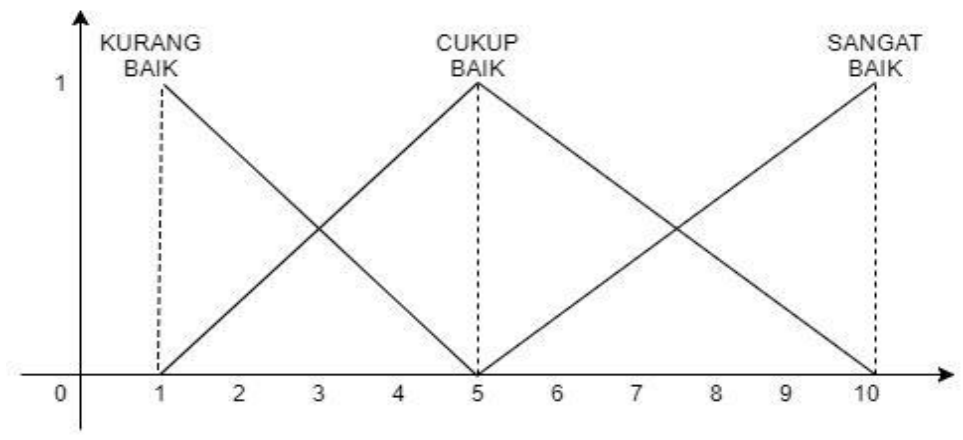

Gambar 2. Fungsi keanggotaaan variabel input

Persamaan untuk mencari nilai keanggotaan Kurang Baik dapat dilihat pada persamaan 1.

$$
\mu[\text { Kurang Baik }]= \begin{cases}1 ; & x \leq 1 \\ \frac{(5-x)}{(5-1)} ; & 1<x<5 \\ 0 ; & x \geq 5\end{cases}
$$

Persamaan untuk mencari nilai keanggotaan Cukup Baik dapat dilihat pada persamaan 2.

$$
\mu[\text { Cukup Baik }]= \begin{cases}1 ; & x=5 \\ \frac{(x-1)}{(5-1)} & x<5 \\ \frac{(10-x)}{(10-5)} & 5<x<10 \\ 0 ; & x \leq 1 \text { atau } x \geq 10\end{cases}
$$

Persamaan untuk mencari nilai keanggotaan Sangat Baik dapat dilihat pada persamaan 3. 


$$
\mu[\text { Sangat Baik }]= \begin{cases}0 ; & x \leq 5 \\ \frac{(x-5)}{(10-5)} ; & 5<x<10 \\ 1 ; & x \geq 10\end{cases}
$$

Setiap nilai pada kriteria diidentifikasikan sesuai dengan representasi pada Gambar 2. Nilai dimasukkan pada persamaan 1, persamaan 2 dan persamaan 3 berdasarkan fungsi keanggotaannya.

\section{Inferensi dengan Metode Tsukamoto}

Aturan fuzzy yang digunakan dalam penelitian sebanyak 54 rule dan dapat dilihat pada Tabel 2.

Tabel 2. Aturan Fuzzy Kepuasan Konsumen

\begin{tabular}{cccccc}
\hline No & $\begin{array}{c}\text { Kualitas } \\
\text { Produk }\end{array}$ & $\begin{array}{c}\text { Kualitas } \\
\text { Pelayanan }\end{array}$ & Harga & Garansi & $\begin{array}{c}\text { Kepuasan } \\
\text { Konsumen }\end{array}$ \\
\hline 1 & Sangat Baik & Sangat Baik & Lebih Murah & Ada & Sangat Puas \\
2 & Sangat Baik & Sangat Baik & Lebih Murah & Tidak Ada & Sangat Puas \\
3 & Sangat Baik & Sangat Baik & Sama & Ada & Sangat Puas \\
4 & Sangat Baik & Sangat Baik & Sama & Tidak Ada & Sangat Puas \\
5 & Sangat Baik & Sangat Baik & Lebih Mahal & Ada & Sangat Puas \\
6 & Sangat Baik & Sangat Baik & Lebih Mahal & Tidak Ada & Puas \\
7 & Sangat Baik & Cukup Baik & Lebih Murah & Ada & Sangat Puas \\
8 & Sangat Baik & Cukup Baik & Lebih Murah & Tidak Ada & Sangat Puas \\
9 & Sangat Baik & Cukup Baik & Sama & Ada & Sangat Puas \\
10 & Sangat Baik & Cukup Baik & Sama & Tidak Ada & Puas \\
11 & Sangat Baik & Cukup Baik & Lebih Mahal & Ada & Puas \\
12 & Sangat Baik & Cukup Baik & Lebih Mahal & Tidak Ada & Puas \\
13 & Sangat Baik & Kurang Baik & Lebih Murah & Ada & Sangat Puas \\
14 & Sangat Baik & Kurang Baik & Lebih Murah & Tidak Ada & Puas \\
15 & Sangat Baik & Kurang Baik & Sama & Ada & Puas \\
16 & Sangat Baik & Kurang Baik & Sama & Tidak Ada & Puas \\
17 & Sangat Baik & Kurang Baik & Lebih Mahal & Ada & Puas \\
18 & Sangat Baik & Kurang Baik & Lebih Mahal & Tidak Ada & Kurang Puas \\
19 & Cukup Baik & Sangat Baik & Lebih Murah & Ada & Sangat Puas \\
20 & Cukup Baik & Sangat Baik & Lebih Murah & Tidak Ada & Sangat Puas \\
• & & & & & \\
• & & & & & \\
• & & & & & Tidak Puas \\
54 & Kurang Baik & Kurang Baik & Lebih Mahal & Tidak & Tidak \\
\hline & & & & & \\
\hline
\end{tabular}

Tahap selanjutnya adalah melakukan pemilihan aturan sesuai berdasarkan nilai kriteria menggunakan metode min dan menentukan nilai $z_{i}$ untuk setiap aturan pada fungsi kenggotaan kepuasan konsumen. Fungsi keanggotaan kepuasan konsumen ditunjukkan pada Gambar 3. 


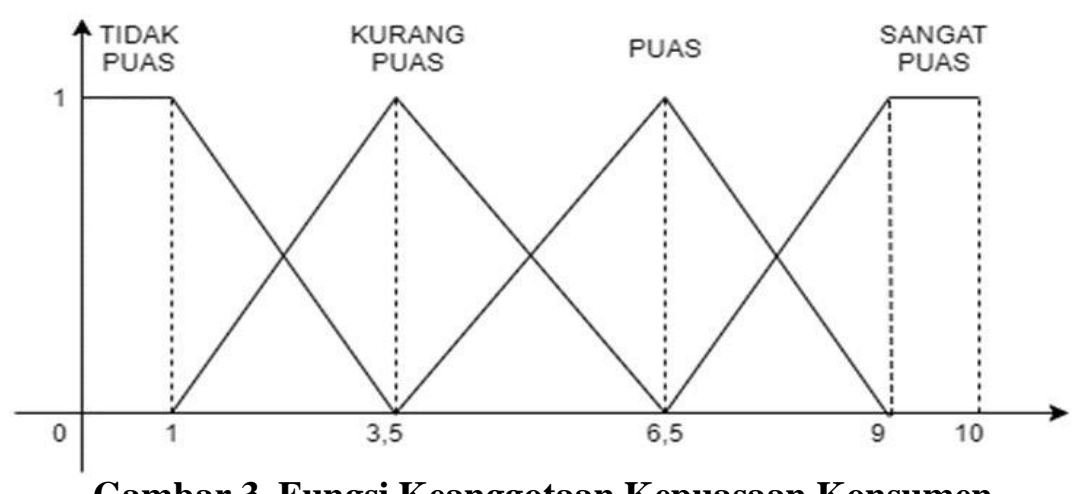

Gambar 3. Fungsi Keanggotaan Kepuasaan Konsumen

Persamaan untuk mencari nilai keanggotaan Tidak Puas dapat dilihat pada persamaan 4.

$$
\mu[\text { Tidak Puas }]= \begin{cases}1 ; & x \leq 1 \\ \frac{(3,5-x)}{(3,5-1)} ; & 1<x<3,5 \\ 0 ; & x \geq 3,5\end{cases}
$$

Persamaan untuk mencari nilai keanggotaan Kurang Puas dapat dilihat pada persamaan 5.

$$
\mu[\text { Kurang Puas }]= \begin{cases}1 ; & x=3,5 \\ \frac{(x-1)}{(3,5-1)} & x<3,5 \\ \frac{(6,5-x)}{(6,5-3,5)} & 3,5<x<6,5 \\ 0 ; & x \leq 1 \text { atau } x \geq 6,5\end{cases}
$$

Persamaan untuk mencari nilai keanggotaan Puas dapat dilihat pada persamaan 6.

$$
\mu[\text { Puas }]= \begin{cases}1 ; & x=6,5 \\ \frac{(x-3,5)}{(6,5-3,5)} ; & x<6,5 \\ \frac{(9-x)}{(9-6,5)} & 6,5<x<9 \\ 0 ; & x \leq 3,5 \text { atau } x \geq 9\end{cases}
$$

Persamaan untuk mencari nilai keanggotaan Sangat Puas dapat dilihat pada persamaan 7.

$$
\mu[\text { Sangat Puas }]= \begin{cases}0 ; & x \leq 6,5 \\ \frac{(x-6,5)}{(9-6,5)} ; & 6,5<x<9 \\ 1 ; & x \geq 9\end{cases}
$$

\section{Defuzzifikasi}

Fungsi yang digunakan pada proses Defuzzifikasi dapat dilihat pada persamaan 8 .

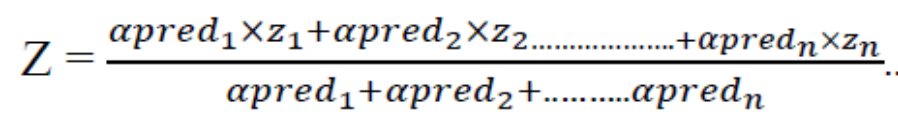

Hasil berupa nilai $\mathrm{Z}$ yang merupakan nilai akhir yang akan digunakan untuk menentukan predikat kepuasan konsumen pada produk knalpot R1 Racing Exhaust Sokaraja. 


\section{Penentuan Kepuasan Konsumen}

Kepuasan konsumen merupakan output yaitu berupa derjat keanggotaan pada himpuynan penilaian kepuasan konsumen dan mengambil kesimpulan berupa tingkat kepuasan konsumen.

\section{Implementasi Sistem}

Saat menjalankan sistem penilaian konsumen, halaman yang pertama kali muncul adalah halaman login. Konsumen dapat melakukan proses penilaian tanpa melakukan proses login. Proses login hanya digunakan untuk admin agar masuk ke dalam aplikasi dan mengakses penuh aplikasi dengan memasukkan username dan password. Tampilan halaman login ditunjukkan pada Gambar 4.

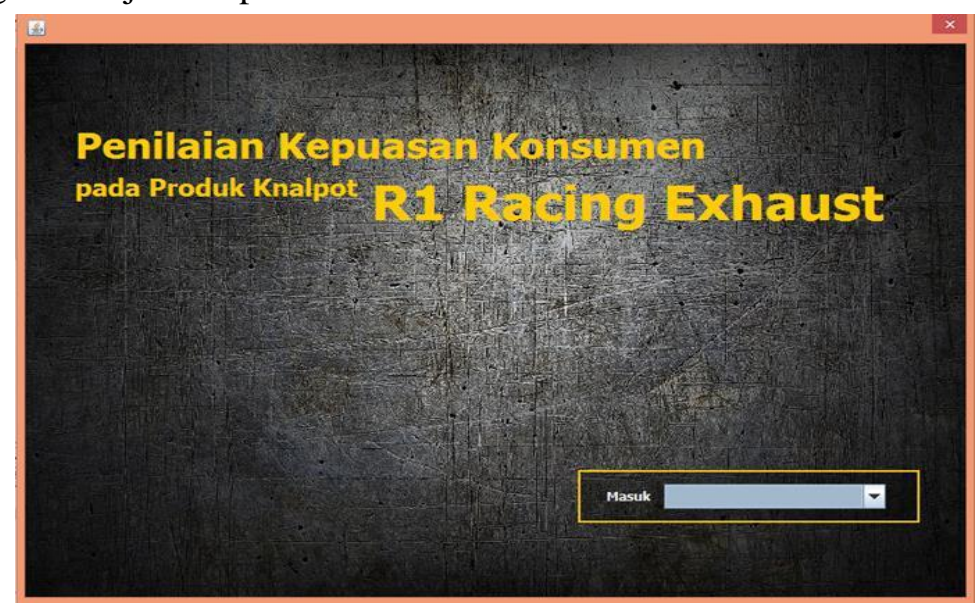

\section{Gambar 4. Halaman Login}

Setelah admin berhasil masuk proses login, maka sistem akan menampilkan halaman menu utama. Pada menu utama terdapat beberapa menu antara lain menu penilaian, menu data penilaian, menu aturan fuzzy dan menu user. Halaman menu utama ditunjukkan pada Gambar 5.

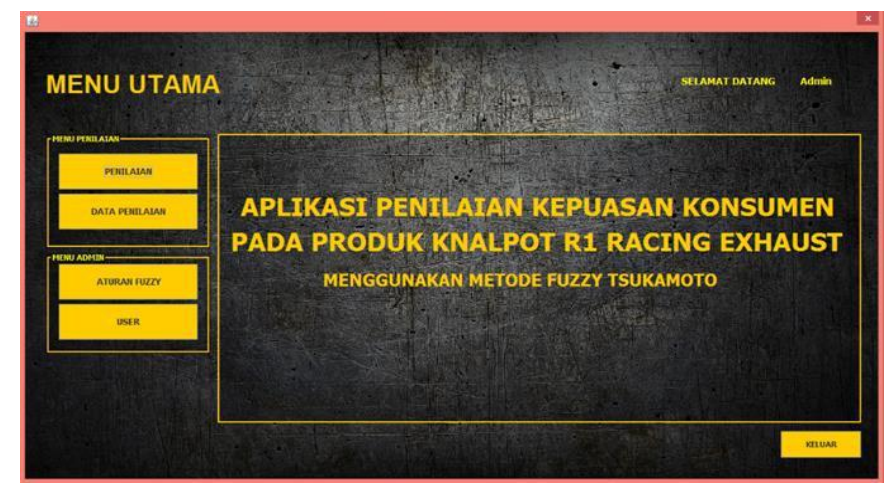

Gambar 5. Halaman Menu Utama

Halaman penilaian adalah halaman yang digunakan untuk proses meng-input penilaian dan proses fuzzifikasi. Terdapat field kualitas produk, kualitas pelayanan, harga dan garansi. Dalam kualitas produk terdapat textfield pewarnaan dan pengelasan. Kualitas pelayanan terdapat textfield waktu pengerjaan, komunikasi, daya tanggap dan keramahan. Harga dan garansi dalam bentuk combo box. Harga terdapat pilihan lebih murah dan lebih mahal sedangkan garansi terdapat pilihan ada dan tidak ada. Saat setelah 
memasukan nilai kriteria maka hasil fuzzifikasi muncul pada kotak derajat keanggotaaan. Halaman penilaian dapat dilihat pada Gambar 6.

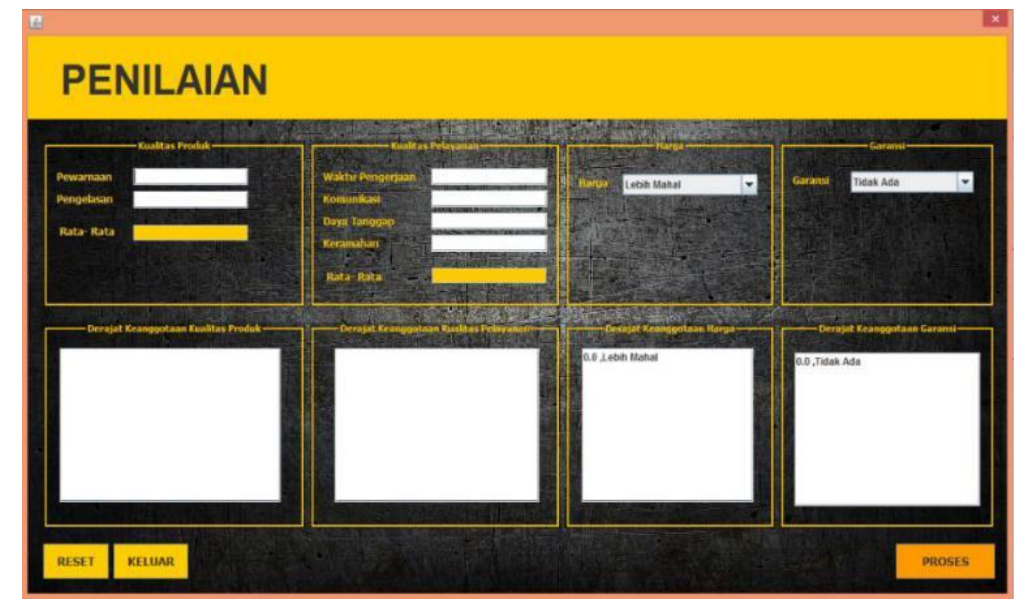

Gambar 6. Halaman Penilaian

Halaman user pada sistem ini merupakan menu yang berada pada halaman utama ketika berhasil melakukan proses login. Halaman user hanya dapat diakses oleh admin untuk memberi hak akses kepada siapa saja aplikasi sistem penilaian kepuasan konsumen digunakan selain proses penilaian. Halaman user terdapat beberapa field antara lain username, password, nama lengkap, alamat, nomer telepon dan jenis kelamin. Halaman user terdapat pada Gambar 7.

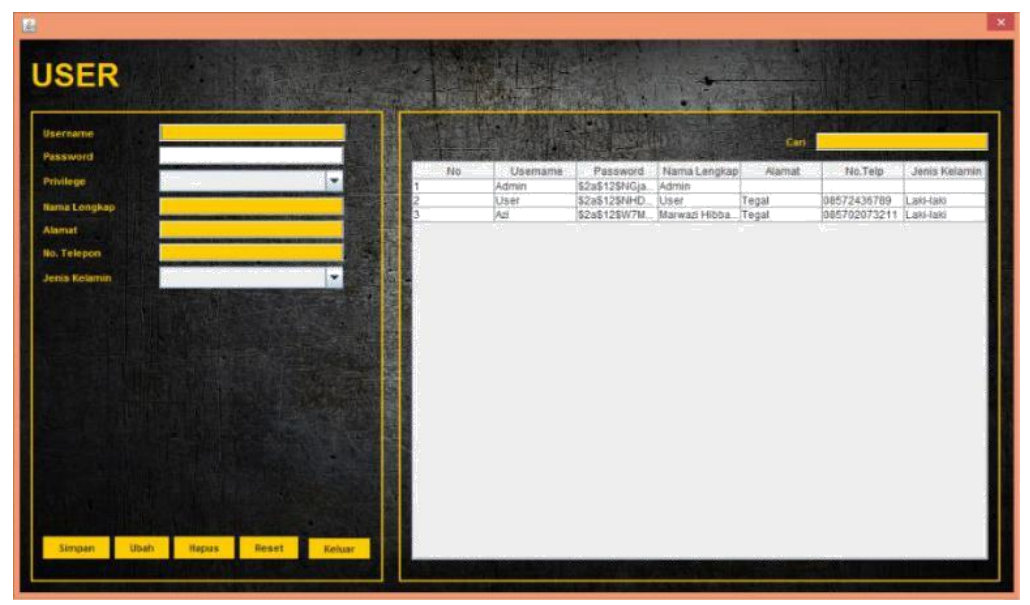

Gambar 7. Halaman User

Halaman aturan fuzzy adalah halaman yang digunakan admin untuk menentukan dan membuat aturan fuzzy atau rule untuk melakukan proses inferensi berdasarkan jenis variabel yang digunakan dalam proses penilaian. Terdapat 5 field combo box yaitu kualitas produk, kualitas pelayanan, harga, garansi dan kepuasan konsumen. Dalam combo box kualitas produk terdapat 3 himpunan fuzzy yang dapat dipilih yaitu sangat baik, cukup baik dan kurang baik. Combo box kualitas pelayanan terdapat 3 himpunan fuzzy yang dapat dipilih yaitu sangat baik, cukup baik dan kurang baik. Combo box harga terdapat 2 pilihan yaitu lebih murah dan lebih mahal. Combo box garansi terdapat 2 pilihan yaitu ada dan tidak ada. Halaman aturan fuzzy dapat dilihat pada Gambar 8 . 


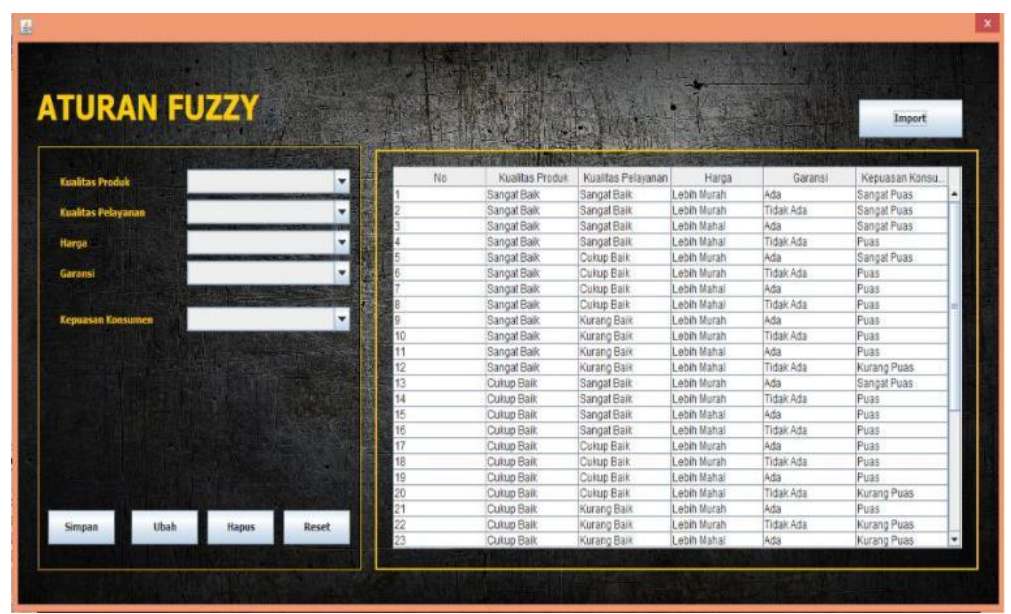

Gambar 8. Halaman Aturan Fuzzy

Halaman data hasil penilaian adalah halaman yang digunakan untuk melihat kumpulan data penilaian yang sudah diproses. Terdapat tanggal awal dan akhir untuk dapat menentukan range waktu data yang akan ditampilkan. Kemudian terdapat button filter untuk menampilkan dan memproses data yang akan dilihat pada tabel data penilaian. Halaman lihat hasil penilaian dapat dilihat pada Gambar 9.

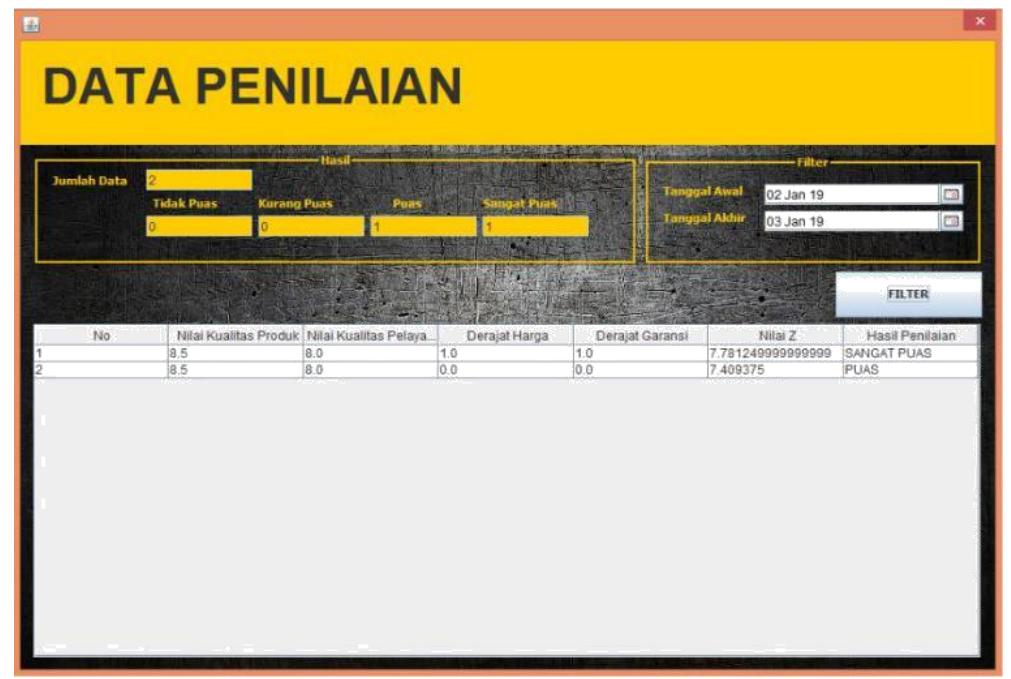

Gambar 9. Halaman Data Hasil Penilaian

\section{KESIMPULAN}

Berdasarkan penelitian yang telah dilakukan dapat diambil kesimpulan bahwa hasil dari penelitian ini dapat membantu pihak industri untuk mengetahui tingkat kepuasan konsumen terhadap produk R1 Racing Exhaust Sokaraja sebagai bahan evaluasi selanjutnya agar dapat mendorong terciptanya loyalitas pelanggan dan meningkatkan laba yang menguntungkan perusahaan. Dari kesimpulan yang telah dikemukakan, saran yang dapat diterapkan untuk penelitian berikutnya yaitu masih dapat dikembangkan dengan menambahkan kriteria dengan pertimbangan agar lebih spesifik dalam penilaian kepuasan konsumen selanjutnya. 


\section{DAFTAR PUSTAKA}

Abza, A.T.P.,2018, Identifikasi Tingkat Kepuasan Pelayanan Konsumen Industri Televisi Berlangganan Dengan Logika Fuzzy Metode Tsukamoto, Jurnal Intra-Tech, ISSN: 2549-0222, Volume II, Nomor 1, April 2018, Hal.16-30.

Agustin, V.R., dan Irawan, W.H., 2015, Aplikasi Pengambilan Keputusan dengan Metode Tsukamoto pada Penentuan Tingkat Kepuasan Pelanggan (Studi Kasus Di Toko Kencana Kediri), CAUCHY, Volume 4, Nomor 1, November 2015, Hal. 10-15.

Curioso, A., Bradford, R., and Galbraith, P., 2010, Expert PHP and MySQL, Wiley Publishing, Indianapolis.

Fasanghari, M., and Roudsari, F.H., 2008, The Fuzzy Evaluation of E-Commerce Customer Satifaction, World Applied Sciences Journal, ISSN: 1818 - 4952, Volume 4, Nomor 2, pp.164-168.

Gronroos, M., 1990, Perceived Service Quality Model, Published Ohio University Press, California.

Ivancevich, J.M., Lorenzi, P., Skinner, S.J., dan Crosby, P.B., 1997, Manajemen Quality and Competitiveness, Irwin, Chicago.

Kotler, P., dan Keller, K.N., 2007, Manajemen Pemasaran, Jilid I, Edisi Kedua belas, PT. Indeks, Jakarta.

Kottler, P., 1997, Manajemen Pemasaran Analisis, Perencanaan, Implementasi dan Kontrol, Prenhallindo, Jakarta.

Kusumadewi, S., dan Purnomo, H., 2004, Aplikasi Logika Fuzzy untuk Pendukung Keputusan, Graha Ilmu, Yogyakarta.

Lupiyoadi, R., 2001, Manajemen Pemasaran Jasa, Teori dan Praktek.,Edisi Pertama, Salemba Empat, Jakarta.

Mustafidah, H., 2013, Konsep Dasar Logika Fuzzy, UMP Press, Yogyakarta.

Mustafidah, H., dan Aryanto, D., 2012, Sistem Inferensi Fuzzy untuk Memprediksi Prestasi Belajar Mahasiswa Berdasarkan Nilai Ujian Nasional, Tes Potensi Akademik, dan Motivasi Belajar, JUITA (Jurnal Informatika), ISSN: 2086-9398, Vol. II, Nomor 1, Mei 2012, Hal. 1-7.

Nofriadi, 2015, Java Fundamental Dengan Netbeans 8.0.2, Deepublish, Yogyakarta.

Parasuraman, A. A., Zeithaml, V., and L. Berry, L, 1985, A Conceptual Model of Service Quality and Its Implications for Future Research, Journal of Marketing, Vol. 49.

Singh, A.P., Sharma, A.K., Singh, V., and Sharma, A., 2014, Analysis of Customer's Satisfaction in Public Transport using Fuzzy Logic for Bhopal City, International Journal of Engineering and Technical Research (IJETR), ISSN: 2321-0869, Volume 2, Nomor 12, December 2014, pp. 272-275.

Sukamto, R.A., dan Salahuddin, M., 2014, Rekayasa Perangkat Lunak Terstruktur dan Berorientasi Objek, Informatika, Bandung.

Suwarsito dan Mustafidah, H., 2015, Determination of Feed Fish Price Based on Feed Formulation with Local Raw Materials using Fuzzy Logic Implementation, IJFAS (International Journal of Fisheries and Aquatic Studies), ISSN: 2347-5129, Volume 3, Nomor 2, September 2015, pp 01-05.

Tjiptono, F., 1994, Strategi Kepuasan Pelanggan, Andi Offset, Yogyakarta.

Tjiptono, F., 2005, Pemasaran Jasa, Bayumedia Publishing, Malang. 